\title{
The relationship between maternal mental health during pregnancy and type of delivery in the suburbs of Bandar Abbas during 2017-2018
}

\author{
Hossein Moameri ${ }^{1}$, Shahrzad Nematollahi ${ }^{1}$, Mehdi Yaseri ${ }^{1}$, Hasan Ahmadi Gharaee ${ }^{1}$, Roya Karimi ${ }^{1}$, \\ Kourosh Holakouie-Naieni*1, 2
}

Received: 24 May 2018

Published: 9 Oct 2019

\section{Abstract}

Background: The effect of maternal mental health during pregnancy on Cesarean section through implications of pre- and postnatal birth have narrowly been investigated. The aim of the present study was to investigate the effect of maternal mental health during pregnancy on the type of delivery in the suburbs of Bandar Abbas.

Methods: This study used data of 200 mothers registered in a prospective cohort study on pregnant women in the suburbs of Bandar Abbas, South of Iran, during 2016-18. The presence of depression, anxiety, or stress in expecting mothers were measured by DASS-21 questionnaire and the outcome defined as having Cesarean section (Cesarean section) was measured at postpartum. The relative risk $(95 \% \mathrm{CI})$ was calculated using Cox regression models. All analyses were performed using STATA statistical package, with a significance level of $5 \%$.

Results: Information of 196 mothers were collected (98\% response rate); the mean age of the participants was $27.28( \pm 5.62)$ years. The prevalence of depression, anxiety, and stress was $13.8 \%$ (27), $40.4 \%$ (40), and 7.6\% (15), respectively. Nearly $40 \%$ of mothers went through Cesarean section. Compared to mothers with good mental health, the risk of Cesarean section was $96 \%$ higher in depressed mothers ( $R R=2,95 \%$ CI: $1.43-2.74)(p=0.001), 81 \%$ higher in anxious mothers $(R R=1.81,95 \%$ CI: $1.29-2.53)(p=0.003)$, and $75 \%$ higher in stressed mothers $(\mathrm{RR}=1.75,95 \% \mathrm{CI}: 0.86-3.56)(\mathrm{p}=0.121)$.

Conclusion: The findings of this study showed that poor mental health, especially anxiety and depression, during pregnancy could increase the risk of Cesarean section. Accordingly, screening protocols for mental health status and prenatal counseling sessions are suggested for pregnant mothers to increase their informed decision on types of delivery.

Keywords: Mental health, Cesarean section, Prospective studies, Cohort studies

Conflicts of Interest: None declared

Funding: National Institute for Medical Research Development (NIMAD)

\section{*This work has been published under CC BY-NC-SA 1.0 license.}

Copyright $\odot$ Iran University of Medical Sciences

Cite this article as: Moameri H, Nematollahi Sh, Yaseri M, Ahmadi Gharaee H, Karimi R, Holakouie-Naieni K. The relationship between maternal mental health during pregnancy and type of delivery in the suburbs of Bandar Abbas during 2017-2018. Med J Islam Repub Iran. 2019 (9 Oct);33:108. https://doi.org/10.47176/mjiri.33.108

\section{Introduction}

Caesarean section (Cesarean section) is a delivery method in which the baby is born by a surgical incision in abdomen and uterus of the mother (1). Despite being useful in some medical occasions (2), there is no evidence of the

Corresponding author: Dr Kourosh Holakouie-Naieni, holakoik@hotmail.com

1. Department of Epidemiology and Biostatistics, School of Public Health, Tehran University of Medical Sciences, Tehran, Iran

2. Bandar Abbas Health Research Station, Bandar Abbas, Iran usefulness of nonmedical Cesarean sections which lead to many complications for the mother and the child. Some studies have shown that Cesarean section is related to increased infant mortality rate (3). Children born by Cesarean

$\uparrow$ What is "already known" in this topic:

- Some factors affect type of delivery.

- Previous studies have examined the relationship between type of delivery and depression and anxiety during pregnancy.

- In Iran, studies have a cross sectional nature in most cases, and prospective studies on this topic are sparse.

$\rightarrow$ What this article adds:

- Depression stress and anxiety during pregnancy seems to play a role in the type of delivery.

- In addition, varied effects were observed for gestational depression, anxiety, and stress on the type of delivery. 
section are more likely to develop diseases related to immune system, such as asthma, laryngitis, and gastroenteritis (4). Cesarean section is related to depression, anxiety, and stress in postpartum period (5), reduced fertility, increased pregnancy intervals (6), and increased risk of stillbirth in later pregnancies (7).

The World Health Organization states that only 10\%$15 \%$ of Cesarean sections are ideal; however, according to the organization's report in 2015, Cesarean section has increased in recent years (2). In some countries, such as Brazil, $43.9 \%$ of pregnancies end with Cesarean section (8). According to recent studies in Iran, the prevalence of Cesarean section is much higher than what is recommended by the World Health Organization (48\%) (9).

Performing Cesarean section is related to many medical and nonmedical factors, including gestational diabetes, hypertension (10), placenta previa (11), vitamin D deficiency (12), history of infertility, history of abortion (13), previous Cesarean section, maternal weight (10), age (9), education, household income, birth weight (14), gestational age (10), preeclampsia (11), number of pregnancies (13), and mental health problems, such as depression (15) and anxiety (16), during pregnancy.

Maternal mental health status during pregnancy is associated with some of the complications in delivery time, most of which lead to Cesarean section (17-20). Some studies have shown that depression in pregnancy increases the likelihood of Cesarean section $(21,22)$ and the risk of emergency Cesarean section (22). In addition, anxiety during pregnancy is not only a risk factor for Cesarean section (16), but it also increases the risk of Cesarean section due to nonmedical reasons (23).

Mental health problems in expecting mothers is increasing worldwide, although the problem is most pronounced in low-income countries $(24,25)$. Increase in Cesarean section incidence is usually followed by more inappropriate maternal and neonatal complications, which requires more postpartum care and increases the financial burden for the health system $(26,27)$. Epidemiological studies need to accurately identify and effectively investigate risk factors for Cesarean section to ensure the prevention of additional complications for the mother and the child. In Iran, studies have been conducted on the relationship between depression during pregnancy and type of delivery (15). However, they are mostly cross sectional and fewer prospective studies have been conducted on this topic (28). The aim of this study was to investigate the effect of maternal mental health during pregnancy (depression, anxiety, and stress) on the type of delivery in the form of DASS scores. In this study, the objective was to use prospective data to find the effects of mental health status on the type of delivery by considering temporality.

\section{Methods}

\section{Design and Procedure}

The present study used data from a pregnancy cohort study entitled" A population-based prospective study to identify contributors to mother and child health in suburban communities in 2016-18". The cohort has been running in 2 suburbs of Bandar Abbas (Chahestaniha and Derakhte-
Sabz) since 2016, and is fully funded by the National Institute for Medical Research Development (NIMAD) (code: 943607). The protocol has also been approved by the ethical committees of Tehran and Hormozgan Universities of Medical Sciences.

The pregnancy cohort was designed to determine the effect of various environmental exposures during gestation on maternal and neonatal health through 4 visits. The details of the methodology and cohort profile have been published elsewhere (29). The present study used the information of the first 200 cohort participants in 2017. Information from the first phase included general characteristics of mothers and household during pregnancy (eg, demographic, socioeconomic status, maternal obstetric history, and maternal nutrition status).

\section{Participants}

Pregnant women residing in the 2 suburban areas of Bandar Abbas (Chahestaniha and Derakht Sabz) who had a successful delivery were included into the study. However, those who migrated from the city for any reason and women who had an abortion were excluded.

The questionnaire for the pregnancy phase included demographic characteristics, socioeconomic status of the household, characteristics of previous and current pregnancy, and maternal mental health. Information on the type of delivery was completed in the second phase (postpartum) through door-to-door interview. Also, to prevent selection bias, those participants who were reluctant to participate were contacted by health care volunteers and invited to resume their participation in the study.

\section{Measures}

The main exposure was defined as self-report of depression, anxiety, or stress, or all were measured in the expecting mother using the Depression, Anxiety, and Stress questionnaire (DASS-21 items) (30). Mental impairment degree of the mother was specified as follows: a total score of 33 or more in all 3 domains, or a score of 10 or more in depression, a score of 15 or more in stress, and a score of 8 or more in anxiety (31). The validity and reliability of the DASS questionnaire in Iranian population has already been confirmed (32).

The dependent variable was the type of delivery (Vaginal or Cesarean section). The covariate variables included maternal age, mother's education, gestational age at birth, history of Cesarean section in mother, mother's abortion history, low birth weight, premature labor history, selfrated health of the mother during pregnancy, regular intake of iron and vitamin D during pregnancy, consumption of multivitamins during pregnancy, and socioeconomic status of the household. The household socioeconomic status was calculated using the principal component analysis (PCA) on 9 household assets (personal car ownership, motorcycle, refrigerator, dishwasher, microwave, personal computer, vacuum cleaner, washing machine, and color television) (33).

Socioeconomic status was divided into good and poor according to the median score, so poor socioeconomic status was defined as below the middle level $(0.999 \geq)$ and good 
socioeconomic status as above the middle $(\geq 1)$. Self-rated health in the mother was measured by the following question: "How do you evaluate your health in general?", with responses on Likert scale (very good, good, moderate, bad, and very bad) (34). The results were further analyzed as a binary variable of good health (including very good and good) and poor health (including moderate, bad, and very bad). Moreover, to prevent the measurement bias, training sessions had been conducted for the interviewees.

\section{Statistical analysis}

For the analyses, the relative risk was calculated using Cox regression models. The log-binomial was proposed at the first step of the research development. However, at the analysis time, it was found that this model had converge problems due to some sparse data in the exposure of interest. Due to the sparse data problem, Cox regression model was used as an alternative. Typically, Cox regression is used for time-to-event data. To use this model, an artificial time variable was constructed where every participant had the same observation time and all events occurred at the same time. With this assumption, the hazard ratio estimated by Cox regression approximates the relative risk (35). To investigate the relationship between variables as univariate, a univariate Cox regression model was used, then, each variable with a significance level of less than 0.2 was included into the Cox regression multivariate model (36). Chisquared test was used to test the correlation between variables. All analyses were performed using STATA version 14.2 considering the significance level of $5 \%$.

\section{Results}

Of the 200 pregnant women who were selected to participate in the study, 196 responded the questionnaire in postpartum period ( $2 \%$ nonresponse). The age ranged from 16 to 42 years; the participants' mean age was $27.28( \pm 5.62)$, and most respondents were in the 25-33 age group. Most respondents reported a good socioeconomic status $(54.08 \%)$. In addition, most mothers had high school and high school diploma education (Table 1$)$.

A total of $117(60.2 \%)$ mothers had vaginal delivery and 79 (39.8\%) had Cesarean section. Also, 154 (87.57\%) mothers reported a good self-rated health. Half of the mothers who had a history of abortion had vaginal labor. More- over, $61.5 \%$ of the mothers with low birth weight had vaginal delivery. Data on previous and recent pregnancies are presented in Table 2 .

The incidence proportion of Cesarean section was 1.71(95\% CI: 1.35-2.78) in mothers with mental disorders, and 1.8 (95\% CI: 1.2-2.72) in mothers with depression during pregnancy. The incidence proportion of Cesarean section was $1.88(95 \% \mathrm{CI}: 1.45,2.77)$ in mothers with anxiety and $1.88(95 \% \mathrm{CI}: 1.30,2.78)$ in mothers with stress during pregnancy.

The variables that remained in the final model included history of Cesarean section, maternal self-rated health, regular iron and multivitamin supplementation during pregnancy, and socioeconomic status.

The results of the final Cox regression model showed that the adjusted risk of Cesarean section in the presence of mental disorders during pregnancy increased by 2 -fold (adjusted relative risk (ARR): 2, 95\% CI: 1.45, 2.77). Additionally, the risk of having a Cesarean section increased by $81 \%$ in the presence of anxiety during pregnancy (ARR: 1.81 ; $95 \%$ CI: $1.29,2.53$ ).

The adjusted risk of Cesarean section was also increased by $96 \%$ in the presence of depression during pregnancy (ARR: 1.96; 95\% CI: 1.43, 2.74), which indicated a statistically significant relationship between depression and Cesarean section. Finally, the adjusted risk of Cesarean section increased by $75 \%$ in the presence of stress during pregnancy (ARR: 1.75; 95\% CI: 0.86, 3.56), which was not statistically significant (Table 3 ).

The adjusted risk of Cesarean section in mothers with previous Cesarean section increased by $71 \%$ (adjusted relative risk (ARR):1.71, 95\% CI: 1.19, 2.47), which demonstrated a statistically significant effect of a history of Cesarean section on current Cesarean section.

The adjusted risk of Cesarean section increased by $39 \%$ in the mothers reporting bad self-rated health during pregnancy (ARR: $1.39 ; 95 \%$ CI: 0.98, 1.98), 22\% in the mothers with bad socioeconomic status (ARR:1.22; 95\% CI: 0.75, $1.76)$, and $17 \%$ in those with irregular consumption of iron in recent pregnancy (ARR: 1.17; 95\% CI: 0.65, 2.13). Moreover, the results showed that the adjusted risk of Cesarean section in mothers with irregular consumption of multivitamin in recent pregnancy decreased by $8 \%$ (ARR: $0.92 ; 95 \%$ CI: $0.50,1.67)$, which was not statistically significant (Table 3).

Table 1. Demographic characteristics of the pregnant women in suburbs of Bandar Abbas in 2017

\begin{tabular}{|c|c|c|c|c|}
\hline \multirow[b]{2}{*}{ Variable } & \multirow[b]{2}{*}{ N (\%) } & \multicolumn{2}{|c|}{ Type of delivery } & \multirow[b]{2}{*}{ p* } \\
\hline & & $\begin{array}{c}\text { Cesarean section } \\
\mathrm{n}(\%) \\
\end{array}$ & $\begin{array}{c}\text { Vaginal } \\
\mathrm{n}(\%)\end{array}$ & \\
\hline \multicolumn{5}{|l|}{ Maternal Age (years) } \\
\hline $16-24$ & $74(37.80)$ & $25(33.78)$ & $49(66.22)$ & 0.336 \\
\hline $25-33$ & $89(45.4)$ & $40(44.94)$ & $49(55.06)$ & \\
\hline $34-42$ & $33(16.80)$ & $14(42.42)$ & $19(57.58)$ & \\
\hline \multicolumn{5}{|l|}{ Socioeconomic status } \\
\hline Low & $90(45.92)$ & $29(40.30)$ & $61(59.70)$ & 0.031 \\
\hline Good & $106(54.08)$ & $50(47.20)$ & $56(52.80)$ & \\
\hline \multicolumn{5}{|l|}{ Maternal Education } \\
\hline Illiterate / reading and writing & $56(30.10)$ & $27(48.21)$ & $29(51.78)$ & 0.652 \\
\hline High school/ diploma & $102(52.04)$ & $32(31.37)$ & $70(68.62)$ & \\
\hline University degree & $38(17.86)$ & $20(52.63)$ & $18(47.36)$ & \\
\hline
\end{tabular}


The effect of maternal mental health on type of delivery

\begin{tabular}{|c|c|c|c|c|}
\hline \multirow[b]{2}{*}{ Variable } & \multirow[b]{2}{*}{ N (\%) } & \multicolumn{2}{|c|}{ Type of delivery } & \multirow[b]{2}{*}{$\mathrm{p}^{*}$} \\
\hline & & $\begin{array}{c}\text { Cesarean section } \\
\mathrm{n}(\%)\end{array}$ & $\begin{array}{c}\text { Vaginal } \\
\text { n (\%) }\end{array}$ & \\
\hline \multicolumn{5}{|c|}{ History of Cesarean section } \\
\hline Yes & $17(8.70)$ & $13(76.47)$ & $4(23.53)$ & 0.003 \\
\hline No & $179(91.30)$ & $66(36.87)$ & $113(63.13)$ & \\
\hline \multicolumn{5}{|l|}{ Gestational age } \\
\hline$\geq 37$ weeks & $173(88.30)$ & $73(42.20)$ & $100(53.80)$ & 0.650 \\
\hline$<37$ weeks & $22(11.70)$ & $6(26.09)$ & $17(73.91)$ & \\
\hline \multicolumn{5}{|c|}{ Iron supplementation in recent pregnancy } \\
\hline Regular & $119(60.70)$ & $41(34.45)$ & $78(65.55)$ & 0.038 \\
\hline Irregular & $78(39.30)$ & $38(49.35)$ & $39(50.65)$ & \\
\hline \multicolumn{5}{|c|}{ Multivitamin supplementation in recent pregnancy } \\
\hline Regular & $116(59.20)$ & $42(35.90)$ & $75(64.10)$ & 0.126 \\
\hline Irregular & $80(40.80)$ & $37(46.84)$ & $42(53.16)$ & \\
\hline \multicolumn{5}{|l|}{ Mental disorder } \\
\hline Yes & $29(14.80)$ & $23(79.31)$ & $6(20.69)$ & 0.015 \\
\hline No & $167(80.20)$ & $56(33.53)$ & $111(66.47)$ & \\
\hline \multicolumn{5}{|l|}{ Depression } \\
\hline Yes & $27(13.78)$ & $21(77.87)$ & $6(22.22)$ & 0.039 \\
\hline No & $196(86.22)$ & $58(34.32)$ & $111(65.68)$ & \\
\hline \multicolumn{5}{|l|}{ Anxiety } \\
\hline Yes & $40(20.41)$ & $27(67.50)$ & $13(32.50)$ & 0.008 \\
\hline No & $156(79.59)$ & $52(37.43)$ & $104(62.57)$ & \\
\hline \multicolumn{5}{|l|}{ Stress } \\
\hline Yes & $15(7.65)$ & $11(73.33)$ & $4(26.67)$ & 0.001 \\
\hline No & $181(92.35)$ & $68(37.57)$ & $113(62.43)$ & \\
\hline \multicolumn{5}{|c|}{ Maternal self-rated health } \\
\hline Good & $154(78.57)$ & $54(35.06)$ & $100(64.94)$ & 0.004 \\
\hline $\mathrm{Bad}$ & $42(21.43)$ & $25(59.52)$ & $17(40.48)$ & \\
\hline
\end{tabular}

Table 3. Unadjusted and adjusted results of Cox regression models for the effect of mental disorders during pregnancy on delivery type (Cesarean section / vaginal)

\begin{tabular}{|c|c|c|c|c|c|c|c|}
\hline \multirow[b]{2}{*}{ Variables } & \multirow[b]{2}{*}{$\mathrm{N}$} & \multicolumn{3}{|c|}{ Univariate } & \multicolumn{3}{|c|}{ Multivariate } \\
\hline & & $\begin{array}{l}\text { Relative } \\
\text { risk }\end{array}$ & $95 \%$ C.I & $\mathrm{p}$ & $\begin{array}{l}\text { Relative } \\
\text { risk }\end{array}$ & $95 \%$ C.I & $\mathrm{p}$ \\
\hline \multicolumn{8}{|l|}{ Mental disorder } \\
\hline No & 167 & 1 & - & - & 1 & - & - \\
\hline Yes & 29 & 1.71 & $1.35-2.78$ & $<0.001$ & 2 & $1.45-2.77$ & 0.001 \\
\hline \multicolumn{8}{|l|}{ Depression } \\
\hline No & 169 & 1 & - & - & 1 & - & - \\
\hline Yes & 27 & 1.8 & $1.2-2.72$ & 0.004 & 1.96 & $1.43-2.74$ & 0.001 \\
\hline \multicolumn{8}{|l|}{ Anxiety } \\
\hline No & 156 & 1 & - & - & 1 & - & - \\
\hline Yes & 40 & 1.88 & $1.31-2.7$ & 0.001 & 1.81 & $1.29-2.53$ & 0.003 \\
\hline \multicolumn{8}{|l|}{ Stress } \\
\hline No & 181 & 1 & - & - & 1 & - & - \\
\hline Yes & 15 & 1.88 & $1.30-2.78$ & 0.001 & 1.75 & $0.86-3.56$ & 0.121 \\
\hline \multicolumn{8}{|c|}{ History of Cesarean section } \\
\hline No & 179 & 1 & - & - & 1 & - & - \\
\hline Yes & 17 & 2.07 & $1.49-2.76$ & $<0.001$ & 1.71 & $1.19-2.47$ & 0.004 \\
\hline \multicolumn{8}{|c|}{ Maternal self-rated health } \\
\hline Good & 154 & 1 & - & - & 1 & - & - \\
\hline Bad & 42 & 1.69 & $1.22-2.36$ & 0.002 & 1.39 & $0.98-1.98$ & 0.060 \\
\hline \multicolumn{8}{|c|}{ Socioeconomic status } \\
\hline Low & 90 & 1 & - & - & 1 & - & - \\
\hline Good & 106 & 1.46 & $1.01-2.01$ & 0.031 & 1.22 & $0.75-1.76$ & 0.264 \\
\hline \multicolumn{8}{|c|}{ Iron supplementation in recent pregnancy } \\
\hline Regular & 119 & 1 & - & - & 1 & - & - \\
\hline Irregular & 77 & 1.43 & $1.02-2$ & 0.024 & 1.17 & $0.65-2.13$ & 0.554 \\
\hline \multicolumn{8}{|c|}{$\begin{array}{l}\text { Multivitamin supplementation in } \\
\text { recent pregnancy }\end{array}$} \\
\hline Regular & 116 & 1 & - & - & 1 & - & - \\
\hline Irregular & 80 & 1.3 & $0.93-1.82$ & 0.012 & 0.92 & $0.50-1.67$ & 0.997 \\
\hline
\end{tabular}

\section{Discussion}

This study was performed on 196 pregnant women who participated in the cohort study of pregnant women in the suburbs of Bandar Abbas. The findings showed that $13.78 \%$ of pregnant women were depressed, $20.41 \%$ had anxiety, and $7.65 \%$ were stressed. Also, the overall prevalence of Cesarean section was $39.8 \%$, which was significantly higher in the group with mental disorders.

Also, there was a significant relationship between maternal mental disorder during pregnancy and Cesarean section delivery, so pregnant mothers with a mental disorder had 
twice more risk for Cesarean section than healthy mothers. Also, the results showed that compared to pregnant mothers who had no mental disorders, the risk of Cesarean section was $81 \%$ higher in the presence of anxiety during pregnancy and $96 \%$ higher in the presence of depression during pregnancy. On the other hand, this study failed to detect any significant effect of stress during pregnancy on the Cesarean section delivery. The possible effect of mental disorders on the Cesarean section can be justified by the effect on some of the risk factors for Cesarean section. As shown by previous studies, mental disorder during pregnancy is related to birth weight, gestational age (37), and preterm delivery(38). In addition, mothers with mental disorders during pregnancy are more likely to have nutritional deficiency, which affects the growth of the fetus and birth weight (39).

Some studies have reported similar findings. The study of Bayrampour et al., showed that maternal mental health in the third trimester is related to Cesarean section, and the risk of emergency Cesarean section in mothers with mental disorder is higher than those without mental disorder. However, they could not find a relationship between mental disorder and elective Cesarean section (22). A study by Storksen et al showed that some of the mental health problems during pregnancy, such as the fear of childbirth, are related to the choice of Cesarean section; hence, mothers who were afraid of natural childbirth were more likely to have Cesarean section (40). At the same time, some studies were not able to find the relationship between the effects of mental health during pregnancy on the type of delivery. In a cross sectional study by Akbarzadeh et al, there was no significant relationship between maternal general health status and type of delivery. The authors concluded that the general health status of expecting mothers was not significantly different in 3 groups of vaginal delivery, emergency Cesarean section, and elective Cesarean section (28). Moreover, in a study by Waldenstrom et al, fear of childbirth was associated with elective Cesarean section, but there was no association between fear of childbirth and delivery with Emergency cesarean section (41).

In this study, there was a significant relationship between anxiety during pregnancy and Cesarean section. Therefore, mothers with anxiety during pregnancy were at higher risk for Cesarean section compared to healthy mothers. Anxiety can increase the risk of Cesarean section through some factors such as fear of childbirth (16), premature delivery, and low birth weight, all of which increase the risk of Cesarean section (42). The effect of anxiety on Cesarean section have already been reported in some studies. For instance, Martini et al reported that pregnant women with anxiety had more Cesarean sections (43). Shaoling et al also showed that having anxiety during pregnancy is a risk factor for nonmedical Cesarean section, but it was not related to medical conditions (44). On the other hand, a study by Johnson and Slade showed no relationship between anxiety and fear of childbirth with both emergency and elective Cesarean section, while other factors that affect the emergency Cesarean section were age of mother, medical risks, and history of Cesarean section (45).
In this study, a significant relationship was found between depression during pregnancy and Cesarean section. Gestational depression may cause preterm delivery, low birth weight (18-20), fetal growth restriction (46), and low Apgar score (18), which are likely to affect the type of delivery. This finding is in agreement with that of Bahrami et al who showed that the probability of Cesarean section in those who had depression during pregnancy was 2.3 times more than others (47). Another study by Yedid Sion et al showed that the prevalence of Cesarean section, preterm delivery, and low birth weight were higher in mothers who were diagnosed with depression during pregnancy (21). However, the findings of the study by $\mathrm{Wu}$ et.al contradicts those of the present study, stating that although most people with depression had Cesarean section (26.5\%), there was no significant relationship between depression during pregnancy and type of delivery (48).

Contrary to the results of previous studies on the significant effect of pregnancy stress on type of delivery $(49,50)$, the present study failed to show a statistically significant relationship between stress during pregnancy and Cesarean section. The possible reason for this finding could be the small number of pregnant women with stress in this study.

One of the strengths of this study was the prospective nature of the query about mental health status, which was measured during pregnancy and before the outcome. Due to the prospective nature of the study, there was less chance for some of the information biases such as recall bias. The other strength of this study was its implementation in the suburban areas and on a population-based sample that provide a high degree of generalizability for the study results. On the other hand, this study had some limitations. The exposures reported in this study were entirely based on selfreport and prone to exposure misclassifications.

\section{Conclusion}

The findings of this study showed that mental health of mothers, especially anxiety and depression, during pregnancy affects the type of delivery. The results support the implementation of prenatal care packages and services focusing on mental health of mothers, especially during pregnancy. Proposed strategies include systematic screening for mental health morbidities in pregnancy and forming a referral framework for psychiatric services. Furthermore, psychiatric counseling sessions for mothers during the last gestational trimester are recommended to increase the awareness of mothers about informed decision-making about their preferred type of delivery.

\section{Acknowledgments}

This cohort project was funded and supported by the National Institute for Medical Research Development (NIMAD). Hereby, the authors thank the institute for its full support and extend their thanks to all study participants for their collaboration and patience.

\section{Conflict of Interests}

The authors declare that they have no competing interests. 


\section{References}

1. Joseph PP, Ann MM, Loise JP, Marion S, EP R. Medical dictionary: A concise and up-to-date guide to medical terms: USA; 1988.

2. Betran A, Torloni M, Zhang J, Gülmezoglu A. WHO Statement on caesarean section rates. BJOG 2015.

3. Kyu HH, Shannon HS, Georgiades K, Boyle MH. Caesarean delivery and neonatal mortality rates in 46 low-and middle-income countries: a propensity-score matching and meta-analysis of demographic and health survey data. Int J Epidemiol. 2013:dyt081.

4. Kristensen K, Henriksen L. Cesarean section and disease associated with immune function. J Allergy Clin Immunol. 2016;137(2):587-90.

5. Clout D, Brown R. Sociodemographic, pregnancy, obstetric, and postnatal predictors of postpartum stress, anxiety and depression in new mothers. J affect Disord. 2015;188:60-7.

6. O’Neill SM, Kearney PM, Kenny LC, Henriksen TB, Lutomski JE, Greene RA, et al. Caesarean delivery and subsequent pregnancy interval: a systematic review and meta-analysis. BMC Pregnancy Childbirth. 2013;13(1):165.

7. Moraitis A, Oliver-Williams C, Wood A, Fleming M, Pell J, Smith G. Previous caesarean delivery and the risk of unexplained stillbirth: retrospective cohort study and meta-analysis. BJOG. 2015;122(11):1467-74.

8. Rebelo F, Da Rocha CMM, Cortes TR, Dutra CL, Kac G. High cesarean prevalence in a national population-based study in Brazil: the role of private practice. Acta Obstet Gynecol Scand. 2010;89(7):903-8.

9. Azami-Aghdash S, Ghojazadeh M, Dehdilani N, Mohammadi M, Abad RAA. Prevalence and Causes of Cesarean Section in Iran: Systematic Review and Meta-Analysis. Iran J Public Health. 2014;43(5):545-55.

10. Tolcher MC, Holbert MR, Weaver AL, McGree ME, Olson JE, ElNashar SA, et al. Predicting cesarean delivery after induction of labor among nulliparous women at term. Obstet Gynecol. 2015;126(5):1059.

11. Janoudi G, Kelly S, Yasseen A, Hamam H, Moretti F, Walker M. Factors associated with increased rates of caesarean section in women of advanced maternal age. J Obstet Gynaecol Canada. 2015;37(6):51726.

12. Scholl TO, Chen X, Stein P. Maternal vitamin D status and delivery by cesarean. Nutrients. 2012;4(4):319-30.

13. Ghadimi M, Rasouli M, Motahar S, Lajevardi Z, Imani A, Chobsaz A, et al. Affecting factors the choice of delivery and attitude of pregnant women admitted to the civil hospitals, the Social Security Organization in 2013. J Sabzevar Uni Med Sci. 2014;21(2).

14. Parissenti TK, Hebisch G, Sell W, Staedele PE, Viereck V, Fehr MK. Risk factors for emergency caesarean section in planned vaginal breech delivery. Arch Gynecol Obstet. 2017;295(1):51-8.

15. Shabangiz A, Ehsanpour S. Association between depression and delivery type. Bimonth J Hormozgan Uni Med Sci. 2014;18(2):140-7.

16. Rubertsson C, Hellström J, Cross M, Sydsjö G. Anxiety in early pregnancy: prevalence and contributing factors. Arch Women's Mental Health. 2014;17(3):221-8.

17. Cole-Lewis HJ, Kershaw TS, Earnshaw VA, Yonkers KA, Lin H, Ickovics JR. Pregnancy-specific stress, preterm birth, and gestational age among high-risk young women. Health Psychol. 2014;33(9):1033.

18. Saeed A, Raana T, Saeed AM, Humayun A. Effect of antenatal depression on maternal dietary intake and neonatal outcome: a prospective cohort. Nutr J. 2016;15(1):64.

19. Flynn HA, McBride N, Cely A, Wang Y, DeCesare J. Relationship of prenatal depression and comorbidities to infant outcomes. CNS Spectr. 2015;20(1):20-8.

20. Accortt EE, Cheadle AC, Schetter CD. Prenatal depression and adverse birth outcomes: an updated systematic review. Mat Child Health J. 2015;19(6):1306-37.

21. Yedid Sion M, Harlev A, Weintraub AY, Sergienko R, Sheiner E. Is antenatal depression associated with adverse obstetric and perinatal outcomes? Matern Fetal Neonatal Med. 2016;29(6):863-7.

22. Bayrampour H, Salmon C, Vinturache A, Tough S. Effect of depressive and anxiety symptoms during pregnancy on risk of obstetric interventions. J Obstet Gynaecol Res. 2015;41(7):1040-8.

23. Zhang S, Huang X, Tan H. Prenatal anxiety and cesarean section with non-medical indication. $J$ Central South Uni Med Sci. 2013;38(10):1070-4

24. Fisher J, Mello MCd, Patel V, Rahman A, Tran T, Holton S, et al. Prevalence and determinants of common perinatal mental disorders in women in low-and lower-middle-income countries: a systematic review. Bullet World Health Organiz. 2012;90(2):139-49.

25. WHO. Mental disorders: WHO; 2017 [cited April 2017]. Available from: http://www.who.int/mediacentre/factsheets/fs396/en/.

26. Liu TC, Chen CS, Lin HC. Does elective caesarean section increase utilization of postpartum maternal medical care? Med Care. 2008;46(4):440-3.

27. Souza J, Gülmezoglu A, Lumbiganon P, Laopaiboon M, Carroli G, Fawole B, et al. WHO Global Survey on Maternal and Perinatal Health Research Group. Caesarean section without medical indications is associated with an increased risk of adverse short-term maternal outcomes: the 2004-2008 WHO Global Survey on Maternal and Perinatal Health. BMC Med. 2010;8(1):71.

28. Akbarzadeh F, Talaei A, Tavassoli F, Jalaliani S, Talebi M, Modarres Gharavi M, et al. Psychological characteristics of women with vaginal delivery, elective and emergency cesarean section. Med J Mashhad Uni Med Sci. 2016;58(10):611-9.

29. Holakouie-Naieni K, Nematollahi S, Mansournia MA, Shekari M, Teimour AM, Alavi A, et al. A Population-based Prospective Study to Identify Contributors to Mother and Child Health in Suburban Communities: The Cohort Profile. Iran J Public Health. 2018;47(3):441.

30. Lovibond PF, Lovibond SH. The structure of negative emotional states: Comparison of the Depression Anxiety Stress Scales (DASS) with the Beck Depression and Anxiety Inventories. Behav Res Ther. 1995;33(3):335-43.

31. Antony MM, Bieling PJ, Cox BJ, Enns MW, Swinson RP. Psychometric properties of the 42-item and 21-item versions of the Depression Anxiety Stress Scales in clinical groups and a community sample. Psychol Assess. 1998;10(2):176.

32. Sahebi A, Asghari MJ, Salari RS. Validation of depression anxiety and stress scale (DASS-21) for an Iranian population. Iran Psychol. 2005;1(4):36-54

33. Vyas S, Kumaranayake L. Constructing socio-economic status indices: how to use principal components analysis. Health Policy Plan. 2006;21(6):459-68.

34. Nedjat S. Is Self-Rated Health a Good Indicator for Assessment of Population Health? A Review Article. Iran J Epidemiol. 2015;10(4):8996.

35. Williamson TS. Log-binomial models: Maximum Likelihood and failed convergence: University of Calgary; 2011.

36. Greenland S, Pearce N. Statistical foundations for model-based adjustments. Ann Rev Public Health. 2015;36:89-108.

37. Rice F, Harold G, Boivin J, Van den Bree M, Hay D, Thapar A. The links between prenatal stress and offspring development and psychopathology: disentangling environmental and inherited influences. Psychol Med. 2010;40(2):335-45.

38. Torche F, Kleinhaus K. Prenatal stress, gestational age and secondary sex ratio: the sex-specific effects of exposure to a natural disaster in early pregnancy. Hum Reprod. 2011;27(2):558-67.

39. Emerson JA, Hurley KM, Caulfield LE, Black MM. Maternal mental health symptoms are positively related to emotional and restrained eating attitudes in a statewide sample of mothers participating in a supplemental nutrition program for women, infants and young children. Matern Child Nutr. 2017;13(1).

40. Størksen HT, Garthus-Niegel S, Adams SS, Vangen S, Eberhard-Gran M. Fear of childbirth and elective caesarean section: a population-based study. BMC Pregnancy Childbirth. 2015;15(1):221.

41. Waldenström U, Hildingsson I, Ryding EL. Antenatal fear of childbirth and its association with subsequent caesarean section and experience of childbirth. BJOG. 2006;113(6):638-46.

42. Ding XX, Wu YL, Xu SJ, Zhu RP, Jia XM, Zhang SF, et al. Maternal anxiety during pregnancy and adverse birth outcomes: a systematic review and meta-analysis of prospective cohort studies. J Affect Disord. 2014;159:103-10.

43. Martini J, Knappe S, Beesdo-Baum K, Lieb R, Wittchen HU. Anxiety disorders before birth and self-perceived distress during pregnancy: associations with maternal depression and obstetric, neonatal and early childhood outcomes. Early Hum Develop. 2010;86(5):305-10.

44. Zhang S, Huang X, Tan H. [Prenatal anxiety and cesarean section with non-medical indication]. J Central South Uni Med Sci. 2013;38(10):1070-4. [Article in Chinese]

45. Johnson R, Slade P. Does fear of childbirth during pregnancy predict emergency caesarean section? BJOG. 2002;109(11):1213-21.

46. Becker M, Weinberger T, Chandy A, Schmukler S. Depression during pregnancy and postpartum. Curr Psychiatry Rep. 2016;18(3):32.

47. Bahrami N, Bahrami S. Correlation between prenatal depression with delivery type and neonatal anthropometric indicators. Koomesh. 2013;15(1):39-45. 
48. Wu J, Viguera A, Riley L, Cohen L, Ecker J. Mood disturbance in pregnancy and the mode of delivery. Am J Obstetr Gynecol. 2002;187(4):864-7.

49. Ko YL, Lin PC, Chen SC. Stress, sleep quality and unplanned Caesarean section in pregnant women. Int J Nurs Pract. 2015;21(5):45461.

50. Saunders TA, Lobel M, Veloso C, Meyer BA. Prenatal maternal stress is associated with delivery analgesia and unplanned cesareans. J Psychosom Obstet Gynecol. 2006;27(3):141-6. 